\title{
Indicações de Transplante de Células-Tronco hematopoéticas em Pediatria: Consenso apresentado no I Encontro de Diretrizes Brasileiras em Transplante de Células-Tronco Hematopoéticas - Sociedade Brasileira de Transplante de Medula Óssea, Rio de Janeiro, 2009
}

\author{
Indications for Pediatric Hematopoietic Stem Cell Transplantation: Consensus presented at the \\ First Meeting on Brazilian Hematopoietic Stem Cell Transplantation Guidelines - Brazilian \\ Society of Bone Marrow Transplantation, Rio de Janeiro, 2009
}

Adriana Seber

Carmem Maria S. Bonfim ${ }^{2}$

Liane E. Daudt ${ }^{3}$

Roseane V. Gouveia ${ }^{4}$

Valéria C. Ginani ${ }^{5}$

Marcos Mauad ${ }^{6}$

Claudio G. Castro $\mathrm{Jr}^{7}$
A Sociedade Brasileira de Transplante de Medula (SBTMO) promoveu o I Encontro de Diretrizes do Transplante de Medula Óssea em 2009. Para revisão das indicações de transplante em Pediatria baseadas em evidências foi constituido grupo de trabalho com oncologistas e hematologistas com experiência em pediatria. Os artigos cientificos foram cuidadosamente avaliados e, para cada doença, foram definidas as evidências para recomendação dos transplantes (de $A$ a $C$ ) e a qualidade destas evidências (de 1 a 3). As recomendações incluem doenças hematológicas malignas e não malignas, tumores sólidos, imunodeficiências e doenças de depósito tratadas com transplantes de células-tronco hematopoéticas, quer autólogos, alogênicos de irmão HLA compativel ou não aparentados (doadores adultos ou sangue de cordão umbilical). Como não existem recomendações uniformemente aceitas em pediatria, não foram incluídas recomendações para transplantes de intensidade reduzida, com manipulação do enxerto e nem parcialmente compativeis. É importante ressaltar que todas as indicações são baseadas no conhecimento atual e podem modificar-se com o tempo. Assim, esta revisão não deve ser utilizada para aplicação direta no cuidado do paciente sem levar em conta características da doença, do doador e fatores de risco do próprio paciente. Este trabalho não deve ainda ser utilizado como documento que limite o acesso do paciente ao transplante adequadamente indicado. Ressaltamos ainda, nesta revisão, diferenças entre transplantes em crianças e em adultos, com algumas recomendações especificas para os transplantes em pediatria. Rev. Bras. Hematol. Hemoter. 2010;32(3):225-239.

Palavras-chave: Transplante; medula óssea; pediatria; leucemia; neoplasias; célulastronco.

\footnotetext{
${ }^{I}$ Hematologia e Oncologia pediátrica. Coordenadora do Centro de Transplante de Medula Óssea do Instituto de Oncologia Pediátrica Graacc - Unifesp - São Paulo-SP.

${ }_{3}^{2}$ Hematologia e Oncologia. Coordenadora do Programa de Transplante de Medula Óssea Pediátrico da Universidade Federal do Paraná. ${ }^{3}$ Hematologia pediátrica. Professor Adjunto do Dep. de Pediatria da UFRGS. Chefe do Serviço de Hematologia do HCPA.

${ }_{5}^{4}$ Hematologia e Oncologia pediátrica. Responsável pelo ambulatório de TMO Pediátrico do IOP-Graacc - Unifesp - São Paulo-SP.

${ }^{5}$ Hematologia e Oncologia pediátrica. Médica do Centro de Transplante de Medula do IOP-Graacc-Unifesp - São Paulo-SP.

${ }_{7}^{6}$ Hematologia e Oncologia pediátrica. Coordenador do Transplante de Medula Pediátrico do Hospital Amaral Carvalho - Jaú, SP.

Hematologia e Oncologia pediátrica. Médico do Serviço de Oncologia Pediátrica do Hospital de Clínicas de Porto Alegre. Coordenador do Comitê de TMO em Pediatria Sobope/SBTMO 2008-2010. Vice-Presidente da Sociedade Brasileira de Oncologia Pediátrica $2008-2010$.
}

Comitê de TMO em Pediatria Sobope/SBTMO.

Correspondência: Adriana Seber

Instituto de Oncologia Pediátrica - Graacc - Unifesp

Rua Botucatu, 743 - Vila Clementino

04023-062 - São Paulo-SP - Brasil

E-mail: adrianaseber@graacc.org.br

Doi: 10.1590/S1516-84842010005000083 


\section{Introdução}

Para o I Encontro de Diretrizes do Transplante de Células-Tronco Hematopoéticas da Sociedade Brasileira de Transplante de Medula Óssea (SBTMO), Rio de Janeiro, 2009 foi constituído grupo de trabalho de oncologistas e hematologistas com experiência em pediatria e as quase duas dezenas de indicações de transplante em pediatria foram divididas entre os autores.

\section{Material e Método}

A revisão de literatura para a elaboração deste consenso baseou-se em artigos indexados, publicados nos últimos dez anos e na literatura nacional, incluindo o que foi publicado em anais de congressos nacionais e internacionais pelo Comitê de TMO da SBTMO/Sobope.

As recomendações para seleção dos artigos para revisão foram: 1) Evitar resumos ou publicações em periódicos que não têm revisores; 2) Só utilizar artigos publicados nos últimos 10 anos; 3) Dar prioridade para trabalhos em que pelo menos $70 \%$ dos pacientes tenham a doença que está sendo avaliada; 4) Evitar estudos com menos de 25 pacientes - exceto se for uma doença rara, para a qual não existam publicações com grande número de casos; 5) Experiência pessoal do serviço ou do País, mesmo não publicada, pode ser utilizada para justificar indicações de transplante, desde que os dados sejam devidamente apresentados. ${ }^{1}$

Foi estabelecido nível de evidência de cada artigo, sendo: 1) Meta-análise, revisão sistemática ou estudo randomizado; 2) Estudo de caso controle ou coorte; 3) Relatos de caso e 4) Opinião de especialista.

A partir do conjunto de trabalhos publicados foi definido o nível de evidências para a recomendação do transplante de células-tronco hematopoéticas (TCTH) e a qualidade destas evidências (Tabela 1).,3

Para cada doença foi elaborado em separado um documento contendo justificativa, recomendações específicas para o diagnóstico em Pediatria, recomendações específicas quanto ao doador e ao tipo de transplante, conclusões, nível de evidência para indicação do TCTH, sumário e referências. Estes documentos, em sua íntegra, serão objeto de publicação em separado. As indicações de transplante em Pediatria já abordadas nos temas discutidos por outros grupos do consenso (hemoglobinopatias, síndromes de falência medular, linfoma Hodgkin, leucemia mieloide crônica) foram revistas pelo grupo, mas não discutidas em plenária e, portanto, não fazem parte da discussão deste documento.

É importante ressaltar que as recomendações de indicação de transplante modificam-se no decorrer do tempo levando em conta os resultados obtidos com tratamento convencional, tratamento de suporte, qualidade de vida a
Tabela 1. Recomendação do transplante de células-tronco hematopoéticas

Qualidade da evidência

1 A recomendação baseia-se em pelo menos um estudo randomizado, meta-análise, revisão sistemática

2 Estudo coorte caso-controle multi-institucional; séries de casos; resultados dramáticos

3 Opinião de profissionais experientes, estudos descritivos ou comitês de especialistas

Evidências para a recomendação

A Boas

B Moderadas

C Escassas

Adaptado de Pappas P. Clinical Practice Guidelines for the Management of Candidiasis: 2009. Update by the Infectious Diseases Society of America. Clinical Infectious Diseases 2009; 48: 503-35 e Canadian Task Force on the Periodic Health Examination. The periodic health examination. Can Med Assoc J 1979; 121:1193254

longo prazo e efeitos tardios. ${ }^{4} \mathrm{~A}$ indicação para cada paciente, individualmente, só deve ser feita após criteriosa avaliação das características da doença, resposta ao tratamento, análise dos doadores disponíveis e do risco do procedimento para aquela criança.

Descrevemos a seguir recomendações específicas para os transplantes em pediatria e o sumário das indicações de transplante em pediatria apresentados em sessão plenária.

\section{Recomendações específicas de consenso na realização de transplantes em Pediatria}

Acreditamos que estas crianças devem ser tratadas somente em centros de excelência, com experiência neste tipo de doença. Para tanto, é preciso que cada centro de transplante atue junto ao seu município, apoiando, junto ao Programa de Tratamento Fora de Domicílio, o encaminhamento da criança para o centro de referência.

Crianças devem ser cuidadas por profissionais e em centros com experiência em pediatria, principalmente aquelas abaixo de $15 \mathrm{~kg}$, que podem ser verdadeiramente colocadas em risco.

A proteção de doadores pediátricos também é fundamental. Não se deve expor as crianças normais ao G-CSF, inserir cateter venoso central e nem submeter à leucoaférese. Além disso, os resultados dos transplantes com medula óssea estão associados a melhores resultados, contra-indicando definitivamente o uso de células-tronco periféricas em transplantes alogênicos pediátricos fora de protocolos de pesquisa específicos. ${ }^{4,5}$

Existem muitas doenças raras em pediatria tratadas com TCHC como, por exemplo, imunodeficiências ou doenças de depósito. Sugerimos que seja estabelecido junto à SBTMO um registro de todos os pacientes transplantados para o tratamento de doenças genéticas raras. 


\section{Recomendações específicas de consenso para transplantes não aparentados em pediatria}

Estudos retrospectivos dos transplantes não aparentados realizados nas últimas décadas revolucionaram a nossa compreensão de compatibilidade HLA. Há muitos anos, o National Marrow Donor Program (NMDP) americano e outros registros nacionais vêm organizando bancos de dados com os resultados dos transplantes não aparentados e armazenando amostras de sangue periférico de pacientes e de seus doadores. Os registros incluem, entre outras informações, características do paciente, doença de base, tipo de transplante, ocorrência de rejeição, doença do enxerto contra o hospedeiro, recidiva e sobrevida.

$\mathrm{Na}$ época, os transplantes foram realizados baseandose na compatibilidade HLA de classe I (A e B) em relação ao nível sorológico ou baixa resolução e HLA de classe II (DR) em alta resolução. Há uma década iniciou-se uma enorme iniciativa para realizar a tipagem retrospectiva do HLA quanto ao nível alélico (DNA com alta resolução em classe I - A, B, C e classe II - DRB1, DQB1 e DPB1) destes indivíduos já transplantados para compreender o impacto das incompatibilidades. ${ }^{6}$

Assim, sabemos hoje que a compatibilidade HLA entre a criança e um doador não aparentado adulto deve ser no mínimo 8/8, ou seja, na tipagem HLA de alta resolução, todos os quatro algarismos de cada antígeno A, B, C e DRB1 devem ser iguais. Idealmente, os antígenos DQB1 também devem ser iguais, constituindo um doador 10/10, que proporciona resultados similares aos transplantes entre irmãos compatíveis. ${ }^{4}$

A compatibilidade HLA tem maior impacto nos resultados de transplantes nas doenças que não estão em fases avançadas e em doenças não malignas. A busca de doador não aparentado não deve estender-se demasiadamente, o que poderia aumentar a chance de recidiva da doença e comprometer ainda mais a chance de cura do paciente.

Quando não há doador voluntário compatível ou quando a urgência clínica não permite que se aguarde a confirmação dos doadores a nível alélico, o transplante pode ser realizado utilizando-se como fonte de células o sangue de cordão umbilical com a melhor compatibilidade possível, mesmo que esta unidade não seja nacional. O cordão umbilical é imunologicamente imaturo, permitindo um grau de incompatibilidade muito maior do que as células de um doador adulto.

A avaliação HLA do cordão leva em conta os antígenos A e B em baixa resolução (dois algarismos) e o DRB1 em alta resolução (quatro algarismos), e os transplantes são possíveis a partir de compatibilidade de apenas 4 dos 6 antígenos. O número de células também é fundamental nos transplantes de cordão, principalmente se há algum grau de incompatibilidade. ${ }^{7}$ Como a seleção de doador adulto ou cordão para cada paciente é bastante complexa, sugerimos que toda busca e a seleção final do melhor doador sejam conduzidas em conjunto pelo Registro de Receptores de Medula Óssea (Rereme) e o centro transplantador.

\section{Leucemia linfoide aguda}

Na leucemia linfoide aguda, o transplante autólogo é contraindicado. Transplantes alogênicos, quer aparentados (doador irmão HLA compatível) ou não aparentados de doadores adultos ou sangue de cordão umbilical, são recomendados para pacientes em primeira remissão e presença de $\mathrm{t}(9 ; 22)$, hipodiploidia extrema ( $<44$ cromossomas), falha indutória (medula M2/3 no dia 29), 11q23 com resposta lenta à terapia ou persistência de doença residual no dia $29>0,1 \%$ (2A) ${ }^{8-12}$ Em segunda remissão de doença de linhagem B, indica-se transplante apenas aparentado se a recidiva foi mais de 36 meses após o diagnóstico inicial ou se for extramedular isolada menos de 18 meses do diagnóstico (2A). ${ }^{13}$ Transplantes aparentados ou não aparentados são indicados em recidivas de leucemia linfoide aguda de linhagem $\mathrm{B}$ com recidiva nos 36 meses que sucedem o diagnóstico e qualquer recidiva medular e recidiva extramedular precoce de linhagem T (1A). Ambos são também indicados em remissão subsequente (2A).

\section{Doenças hematológicas malignas (Tabela 2)}

\section{Leucemia mieloide aguda}

Não há consenso quanto à indicação de transplante autólogo em crianças com leucemia mieloide aguda.

Os transplantes alogênicos são indicados em $1^{\mathrm{a}}$ remissão com doador familiar ou não aparentado se o paciente apresentar fatores de alto risco: ${ }^{14}-7,-5$, cariótipo complexo, secundário a SMD ou QT prévia; LMA-M0 ${ }^{15} \mathrm{M} 6, \mathrm{M} 7{ }^{16}$ sem síndrome de Down e $<4$ anos; FLT3 ITD $>04 ;>15 \%$ células blásticas ao final da primeira indução (2A). ${ }^{17}$

Para indicação do TMO não aparentado em primeira remissão devem ser levados em consideração fonte de células, histocompatibilidade, número de células (cordão) e experiência do centro.

Somente transplantes aparentados são indicados para crianças com risco intermediário, ${ }^{18}$ isto é, sem fatores de alto risco e sem fatores de baixo risco $[\mathrm{t}(15 ; 17)$; $\mathrm{t}(8 ; 21)$, inv16; Síndrome de Down], sem fatores de risco moleculares ou à imunofenotipagem (2A). Na segunda remissão ou em remissões subsequentes, indicamos transplante com qualquer doador (2A).

Pacientes com doença refratária têm pior prognóstico e sugerimos que sejam incluídos em protocolos clínicos específicos (3B).

\section{Síndromes mielodisplásicas}

A classificação das síndromes mielodisplásicas em pediatria difere da utilizada em adultos, ${ }^{19}$ compreendendo citopenias refratárias, anemia refratária com excesso de blastos 
Tabela 2. Critérios de indicação de transplante de células-tronco hematopoéticas em doenças hematológicas malignas em pediatria

\begin{tabular}{|c|c|c|c|c|}
\hline Doença & Fase da doença/ Critério de indicação & $\begin{array}{l}\text { Transplante } \\
\text { alogênico com } \\
\text { irmão HLA } \\
\text { compatível }\end{array}$ & $\begin{array}{l}\text { Transplante } \\
\text { alogênico com } \\
\text { doador não } \\
\text { aparentado }\end{array}$ & $\begin{array}{l}\text { Transplante } \\
\text { autólogo }\end{array}$ \\
\hline \multirow[t]{3}{*}{ Leucemia linfoide aguda } & $\begin{array}{l}1^{a} \text { remissão } \\
\text { Muito alto risco: t(9;22), <44 cromossomos, falha indutória } \\
\text { (medula M2/M3 D29), 11q23 com resposta lenta ou DRM } \\
>0,1 \% \text { no D29 }\end{array}$ & $2 \mathrm{~A}$ & $2 \mathrm{~A}$ & $\mathrm{NI}$ \\
\hline & $\begin{array}{l}\geq 2^{a} \text { remissão } \\
\text { Linhagem B com recidiva após remissão com duração < } \\
36 \text { meses ou qualquer LLA de linhagem } T\end{array}$ & $1 \mathrm{~A}$ & $2 \mathrm{~A}$ & $\mathrm{NI}$ \\
\hline & $\begin{array}{l}\geq 2^{a} \text { remissão } \\
\text { Linhagem } B \text { com recidiva }>36 \text { meses do diagnóstico ou } \\
\text { extramedular isolada }<18 \text { meses do diagnóstico }\end{array}$ & $2 \mathrm{~A}$ & $\mathrm{NI}$ & $\mathrm{NI}$ \\
\hline \multirow[t]{3}{*}{ Leucemia mieloide aguda } & $\begin{array}{l}1^{a} \text { remissão } \\
\text { Alto risco: }-7,-5 \text {, cariótipo complexo, LMA secundária; } \\
\text { LMA-M0, M6 e M7 sem Síndrome de Down e }<4 \text { anos; } \\
\text { FLT-ITD }>4 ;>15 \% \text { blastos ao final da } 1^{\mathrm{a}} \text { indução }\end{array}$ & $2 \mathrm{~A}$ & $2 \mathrm{~A}$ & $\mathrm{NI}$ \\
\hline & $\begin{array}{l}1^{a} \text { remissão } \\
\text { Sem fatores de alto risco (acima) } \\
\text { Sem fatores de baixo risco (abaixo) }\end{array}$ & $2 \mathrm{~A}$ & $\mathrm{NI}$ & $\mathrm{NI}$ \\
\hline & $\begin{array}{l}1^{a} \text { remissão } \\
\mathrm{t}(15 ; 17) ; \mathrm{t}(8 ; 21) ; \text { inv16; Síndrome de Down } \\
\geq 2^{2} \text { remissão } \\
\text { Doença refratária }\end{array}$ & $\begin{array}{l}\mathrm{NI} \\
2 \mathrm{~A} \\
3 \mathrm{~B}\end{array}$ & $\begin{array}{l}\mathrm{NI} \\
2 \mathrm{~A} \\
3 \mathrm{~B}\end{array}$ & $\begin{array}{l}\text { Não há } \\
\text { consenso } \\
2 \mathrm{~A} \\
\mathrm{NI}\end{array}$ \\
\hline \multirow[t]{2}{*}{ Leucemia mieloide crônica } & $1^{a}$ fase crônica & $\begin{array}{l}\text { Não há } \\
\text { consenso }\end{array}$ & $\mathrm{NI}$ & $\mathrm{NI}$ \\
\hline & $\begin{array}{l}\text { Falha à terapia com inibidores de tirosina quinase ou } \\
\text { progressão de doença }\end{array}$ & $2 \mathrm{~A}$ & $2 \mathrm{~A}$ & $\mathrm{NI}$ \\
\hline $\begin{array}{l}\text { Síndromes mielodisplásicas } \\
\text { Citopenias refratárias }\end{array}$ & $\begin{array}{l}\text { Monossomia 7, cariótipo complexo, neutropenia } \\
<1000 / \mathrm{mm}^{3} \text {, necessidade transfusional - Ao diagnóstico }\end{array}$ & $2 \mathrm{~A}$ & $2 \mathrm{~A}$ & $\mathrm{NI}$ \\
\hline $\begin{array}{l}\text { Anemia refratária com } \\
\text { sideroblastos em anel }\end{array}$ & Diagnóstico provável de mitocondriopatia & $\mathrm{NI}$ & $\mathrm{NI}$ & $\mathrm{NI}$ \\
\hline $\begin{array}{l}\text { Anemia refratária com excesso } \\
\text { de blastos e excesso de } \\
\text { blastos em transformação }\end{array}$ & Ao diagnóstico & $2 \mathrm{~A}$ & $2 \mathrm{~A}$ & $\mathrm{NI}$ \\
\hline $\begin{array}{l}\text { Síndrome de Down: síndrome } \\
\text { mielodisplásica, síndrome } \\
\text { mieloproliferativa e leucemia } \\
\text { mieloide aguda }\end{array}$ & $\geq 2^{a}$ remissão (TCTH nunca é indicado na $1^{a}$ remissão & $2 \mathrm{~A}$ & $2 \mathrm{~A}$ & $\mathrm{NI}$ \\
\hline $\begin{array}{l}\text { Síndromes mieloproliferativas } \\
\text { Leucemia mielomonocítica } \\
\text { juvenil }\end{array}$ & Ao diagnóstico & $2 \mathrm{~A}$ & $2 \mathrm{~A}$ & $\mathrm{NI}$ \\
\hline $\begin{array}{l}\text { Leucemia mielomonocítica } \\
\text { crônica do tipo adulto }\end{array}$ & Ao diagnóstico & $2 \mathrm{~A}$ & $2 \mathrm{~A}$ & $\mathrm{NI}$ \\
\hline $\begin{array}{l}\text { Leucemia mieloide crônica } \\
\text { bcr-abl negativo }\end{array}$ & Ao diagnóstico & $2 A$ & $2 \mathrm{~A}$ & $\mathrm{NI}$ \\
\hline $\begin{array}{l}\text { Sindromes hemofagocíticas } \\
\text { Classe I: Histiocitose de } \\
\text { células de Langerhans }\end{array}$ & $\begin{array}{l}\text { Acometimento sistêmico (hematopoético, fígado, } \\
\text { baço e pulmões) e falha da terapia convencional }\end{array}$ & $2 A$ & $2 \mathrm{~A}$ & $\mathrm{NI}$ \\
\hline $\begin{array}{l}\text { Classe II: Linfohistiocitose } \\
\text { eritrofagocítica familial }\end{array}$ & Em $1^{a}$ remissão após quimioterapia & $2 \mathrm{~A}$ & $2 \mathrm{~A}$ & $\mathrm{NI}$ \\
\hline
\end{tabular}


Tabela 2. Critérios de indicação de transplante de células-tronco hematopoéticas em doenças hematológicas malignas em pediatria (continuação)

\begin{tabular}{|c|c|c|c|c|}
\hline Doença & Fase da doença/ Critério de indicação & $\begin{array}{l}\text { Transplante } \\
\text { alogênico com } \\
\text { irmão HLA } \\
\text { compatível }\end{array}$ & $\begin{array}{l}\text { Transplante } \\
\text { alogênico com } \\
\text { doador não } \\
\text { aparentado }\end{array}$ & $\begin{array}{c}\text { Transplante } \\
\text { autólogo }\end{array}$ \\
\hline \multicolumn{5}{|l|}{ Linfomas não-Hodgkin } \\
\hline Linfoma de Burkitt & $\begin{array}{l}2^{a} \text { remissão } \\
\text { OBS: Linfoma de Burkitt com infiltração medular > 25\% } \\
\text { deve ser transplantado como LLA }\end{array}$ & $3 \mathrm{C}$ & $\mathrm{NI}$ & $2 \mathrm{~A}$ \\
\hline \multirow{2}{*}{$\begin{array}{l}\text { Linfoma difuso de } \\
\text { grandes células }\end{array}$} & $2^{a}$ remissão & $\mathrm{NI}$ & $\mathrm{NI}$ & $2 \mathrm{~A}$ \\
\hline & $\begin{array}{l}\text { Recidiva após TCTH autólogo } \\
\text { Doenças refratárias }\end{array}$ & $3 \mathrm{C}$ & $\begin{array}{l}\mathrm{NI} \\
\mathrm{NI}\end{array}$ & $\begin{array}{l}\mathrm{NI} \\
\mathrm{NI}\end{array}$ \\
\hline $\begin{array}{l}\text { Linfoma anaplásico de } \\
\text { grandes células }\end{array}$ & $\geq 2^{a}$ remissão; doença refratária & $2 \mathrm{~A}$ & $2 \mathrm{~B}$ & $2 \mathrm{~B}$ \\
\hline Linfoma linfoblástico & $\geq 2^{a}$ remissão & $2 \mathrm{~A}$ & $2 \mathrm{~A}$ & $3 C$ \\
\hline \multirow[t]{4}{*}{ Linfoma Hodgkin } & $\begin{array}{l}\text { Doença com refratariedade primária, mas responsiva a } \\
\text { terapia de salvamento; } \geq 2^{\mathrm{a}} \text { remissão }\end{array}$ & $\mathrm{NI}$ & $\mathrm{NI}$ & $2 \mathrm{~A}$ \\
\hline & $2^{\mathrm{a}}$ remissão após recidiva em área não irradiada & $\mathrm{NI}$ & $\mathrm{NI}$ & $2 \mathrm{~B}$ \\
\hline & $\begin{array}{l}2^{\mathrm{a}} \text { remissão recidiva tardia ( }>1 \text { ano após término do } \\
1^{0} \text { tratamento) }\end{array}$ & $\mathrm{NI}$ & $\mathrm{NI}$ & $2 \mathrm{C}$ \\
\hline & $\begin{array}{l}\text { Recidiva após TCTH autólogo, falha na coleta de } \\
\text { células autólogas e múltiplas recidivas }\end{array}$ & $2 \mathrm{~B}$ & 2B & $\mathrm{NI}$ \\
\hline
\end{tabular}

$\mathrm{Nl}$ - não indicado fora de protocolos específicos de investigação

e excesso de blastos em transformação, síndrome mieloproliferativa transitória da síndrome de Down, leucemia mieloide aguda da Síndrome de Down e síndromes mieloproliferativas.

Nas citopenias refratárias pode ser utilizado tratamento imunossupressor segundo protocolo clínico específico, incluindo sempre boa quelação de ferro. ${ }^{20}$

Os transplantes alogênicos (aparentados ou não) são indicados para crianças com monossomia 7, cariótipo complexo, neutropenia $<1000 / \mathrm{mm}^{3}$ ou com necessidade transfusional (2A). Não há consenso se a melhor estratégia seria transplante com regime preparatório de intensidade reduzida ou mieloablativo convencional. ${ }^{21}$

Em crianças com anemia refratária com sideroblastos em anel e presença de vacuolização celular, investigar mitocondriopatias, nas quais o transplante não é indicado por não modificar a história natural da doença. ${ }^{22} \mathrm{~A}$ anemia refratária com excesso de blastos e excesso de blastos em transformação deve ser tratada com transplante alogênico, aparentado ou não $(2 \mathrm{~A}){ }^{23}$

\section{Sindromes mieloproliferativas}

As síndromes mieloproliferativas compreendem a leucemia mielomonocítica juvenil, leucemia mielomonocítica crônica tipo adulto e leucemia mieloide crônica bcr-abl positivo ou negativo. Para todas, o tratamento indicado é transplante alogênico aparentado ou não (2A). ${ }^{24}$

Não há consenso entre pediatras se o melhor tratamento inicial da $1^{\mathrm{a}}$ fase crônica da leucemia mieloide crônica deva ser com inibidores da tirosina quinase (TK) ou transplante alogênico aparentado. ${ }^{25,26} \mathrm{O}$ uso de hidroxiureia isoladamente é contraindicado. Pacientes sem doador compatível devem fazer uso de inibidor TK (2A), mas a monitorização tem que ser cuidadosa. Em fases avançadas, o inibidor TK apropriado deve ser seguido de transplante alogênico aparentado ou não $(2 \mathrm{~A}) .^{27}$

\section{Histiocitoses}

Existem três formas de histiocitose em pediatria: histiocitose de células de Langerhans, linfohistiocitose hemofagocítica familiar e a forma adquirida. A histiocitose de células de Langerhans habitualmente responde muito bem ao tratamento quimioterápico. Para casos de doença multissistêmica refratária ao tratamento de $1^{\mathrm{a}}$ linha, o transplante alogênico aparentado ou não é indicado (2B). Como a doença pode ser muito agressiva, sugerimos iniciar precocemente busca de doador familiar ou não aparentado em pacientes de mau prognóstico.

A linfohistiocitose hemofagocítica familiar deve ser tratada com quimioterapia agressiva, seguida de transplante alogênico aparentado ou não para todos os pacientes (2A), preferencialmente, em remissão. Entretanto, é necessário pesquisar a doença em doadores familiares. Está em estudo qual seria o melhor regime preparatório, de intensidade reduzida para pacientes em remissão (Fludarabina-melfalano vs bussulfano-ciclofosfamida).

A linfohistiocitose hemofagocítica adquirida é tratada somente com quimioterapia. Transplante aparentado ou não 
só está indicado para doentes que não respondem à quimioterapia (2A). ${ }^{28}$

\section{Linfomas de Hodgkin}

Os linfomas de Hodgkin têm indicação de transplante autólogo a partir da $2^{\mathrm{a}}$ remissão ou já em $1^{\mathrm{a}}$ remissão se a doença foi inicialmente refratária à quimioterapia (2A). Há controvérsia quanto à indicação em recidivas tardias (mais de um ano após o $1^{\circ}$ tratamento $-2 \mathrm{C}$ ) e recidiva em áreas não irradiadas (2B). ${ }^{29-31}$ A recidiva em sítios extranodais ou com sintomas B são consideradas de mau prognóstico. ${ }^{32}$

Transplantes alogênicos aparentados ou não são indicados para recidiva após transplante autólogo, incapacidade de coletar células-tronco autólogas da medula ou sangue periférico ou na presença de múltiplas recidivas (2B). ${ }^{33,34}$

\section{Linfomas não Hodgkin}

$\mathrm{O}$ linfoma de Burkitt tem indicação de transplante autólogo somente em $2^{\mathrm{a}}$ remissão (2A). ${ }^{35}$ Não existe indicação de transplante em doenças refratárias. Há raros relatos de caso de transplantes alogênicos (3C). A infiltração medular $>25 \%$ (LLA-L3) é tratada, por outro lado, como leucemia linfoide aguda. Talvez exista um papel importante dos anticorpos anti-CD20 após a $1^{\mathrm{a}}$ recidiva, para que seja atingida a $2^{\mathrm{a}}$ remissão, possibilitando o transplante. ${ }^{36}$ Talvez exista ainda papel dos anticorpos anti-CD20 como manutenção após o procedimento.

No linfoma difuso de grandes células é indicado transplante autólogo para pacientes em $2^{\mathrm{a}}$ remissão $(2 \mathrm{~A})$ e contraindicado na presença de doença refratária. Transplantes alogênicos são indicados para recidivas após transplante autólogo (2C) e doenças refratárias (3C). Também não se sabe o papel dos anticorpos anti-CD20 na reindução e após o transplante. ${ }^{37}$

O linfoma anaplásico de grandes células tem indicação de transplante alogênico aparentado (2A) ou não aparentado e/ou autólogo (2B) para crianças após a $2^{\mathrm{a}}$ remissão ou com doença refratária. Como existe efeito do enxerto contra linfoma anaplásico, transplante com doador aparentado deve ter preferência em relação ao transplante autólogo. ${ }^{38-40}$

Linfoma linfoblástico deve ser tratado com transplante alogênico aparentado ou não (2A) ou autólogo (3C) a partir da $2^{\mathrm{a}}$ remissão. ${ }^{41,42}$

\section{Tumores sólidos pediátricos (Tabela 3)}

Para o tratamento de tumores sólidos pediátricos, a maioria dos estudos utiliza o transplante autólogo, sendo o uso do transplante alogênico relatado esporadicamente e podendo seu uso ser considerado investigacional. ${ }^{4}$

É consenso do grupo pediátrico que o transplante autólogo só pode ser indicado no tratamento de tumores sólidos na evidência de uma resposta clínica parcial ou completa à quimioterapia. ${ }^{43,44}$

\section{Neuroblastoma}

No neuroblastoma de alto risco, a publicação dos resultados do protocolo randomizado e acompanhamento após o transplante de 10 anos confirmou a efetividade do transplante autólogo em primeira remissão (resposta completa ou

Tabela 3. Critérios de indicação de transplante de células-tronco hematopoéticas em tumores sólidos em pediatria

\begin{tabular}{|c|c|c|}
\hline Doença & Fase da doença/ Critério de indicação & Transplante autólogo \\
\hline Neuroblastoma & $\begin{array}{l}1^{\mathrm{a}} \text { remissão de doença de alto risco (estadio } 4, \text { myc-N amplificado) } \\
2^{\mathrm{a}} \text { remissão }\end{array}$ & $\begin{array}{c}1 \mathrm{~A} \\
\text { Não há consenso }\end{array}$ \\
\hline Tumor de células germinativas & $\geq 2^{\mathrm{a}}$ remissão ou doença refratária não progressiva & $2 \mathrm{~B}$ \\
\hline \multicolumn{3}{|c|}{ Tumores do Sistema Nervoso Central* } \\
\hline \multirow[t]{2}{*}{ Meduloblastoma/ PNET } & Crianças $<4$ anos para evitar efeito deletério da radioterapia & 2B \\
\hline & $2^{\mathrm{a}}$ remissão & $2 \mathrm{C}$ \\
\hline Pinealoblastoma & $\geq 1^{\mathrm{a}}$ remissão & 2B \\
\hline Tumor teratoide-rabdoide & $1^{\mathrm{a}}$ remissão & 2B \\
\hline Tumores de células germinativas & $\geq 2^{a}$ remissão & $2 \mathrm{~B}$ \\
\hline Gliomas de alto grau & Após ressecção completa ou muito boa & 2C \\
\hline Retinoblastoma & $1^{\text {a }}$ remissão de doença extraocular & $2 \mathrm{C}$ \\
\hline Sarcoma de Ewing & $\begin{array}{l}1^{\mathrm{a}} \text { remissão de doença metastática } \\
2^{\mathrm{a}} \text { remissão com controle local da doença }\end{array}$ & $\begin{array}{l}2 \mathrm{C} \\
2 \mathrm{~B}\end{array}$ \\
\hline Tumor de Wilms & $\begin{array}{l}\text { Recidiva em menos de } 1 \text { ano em crianças que receberam radioterapia } \\
\text { abdominal ou com histologia desfavorável }\end{array}$ & $2 \mathrm{~B}$ \\
\hline
\end{tabular}

Obs.: Transplantes alogênicos não são realizados no tratamento de tumores sólidos pediátricos fora de contexto investigacional. Nos tumores de sistema nervoso central não há indicação de transplante no tratamento de ependimomas, gliomas de tronco, meduloblastomas recidivados sem resposta à quimioterapia, pacientes com baixa performance e gliomas de alto grau com grande volume tumoral 
resposta parcial muito boa à quimioterapia).$^{45}$ Os critérios de risco estão bem definidos e incluem idade, estadiamento, histologia e presença da amplificação do gene $n$-myc (http:/ /www.cancer.gov/cancertopics/pdq/treatment/neuroblastoma /Health Professional/page4). Após o transplante, é fortemente recomendado o uso de manutenção com isotretinoína (ácido cis-retinoico e não o ácido trans-retinoico utilizado na LMA-M3). O regime de condicionamento mais utilizado combina etoposide, melfalano e carboplatina, mas a combinação com bussulfano e melfalano parece ser igualmente efetiva (1A). ${ }^{46}$ Não há consenso de indicação de TMO em segunda remissão.

\section{Tumores de células germinativas}

A maioria dos estudos de tumores de células germinativas extracranianos é em pacientes adultos. $\mathrm{O}$ transplante parece ser benéfico em pacientes após a primeira ou segunda recidiva, com resposta à quimioterapia e com a menor quantidade de doença residual (2B). ${ }^{47}$

\section{Tumores do sistema nervoso central}

Não há estudos randomizados comparando o tratamento de tumores do sistema nervoso central com quimioterapia convencional $v s$. transplante devido ao pequeno número de pacientes. O transplante autólogo foi o mais estudado. A maioria dos esquemas de condicionamento utiliza a tiotepa. ${ }^{48,49}$ Os transplantes autólogos são indicados nas seguintes doenças: meduloblastoma em pacientes menores que 4 anos de idade (2B), ${ }^{50}$ pinealoblastoma (2B), ${ }^{51}$ tumores rabdoides do sistema nervoso central em primeira remissão (2B), tumores de células germinativas do sistema nervoso central recidivados (2B), meduloblastoma/PNET recidivado não submetido à radioterapia, bom respondedor à quimioterapia de resgate $(2 \mathrm{C}),{ }^{52}$ gliomas de alto grau com ressecção completa ou muito boa (2C).

Em outras doenças há evidências de ausência de benefício do uso de altas doses, apesar do número restrito de pacientes: ependimoma, gliomas de tronco, PNET e meduloblastomas recidivados que não respondem à quimioterapia de segunda linha, pacientes com baixa performance, gliomas de alto grau com grande volume tumoral.

\section{Retinoblastoma}

O retinoblastoma é uma doença com índices de cura elevados. Séries de casos, utilizando o transplante autólogo como estratégia de tratamento em pacientes metastáticos mostrou bons resultados $(2 \mathrm{C}) .{ }^{53}$

\section{Tumores da família do sarcoma de Ewing}

Para os tumores da família do sarcoma de Ewing, o estudo Euro-Ewing deverá trazer informações significativas a respeito do uso do transplante. ${ }^{54}$ Pacientes com metástases pulmonares transplantados em primeira remissão parecem ser o grupo com maior benefício. Aqueles com metástases ósseas e/ou em medula óssea têm aparentemente pior prognóstico..$^{55}$

$\mathrm{O}$ uso em pacientes recidivados parece ser benéfico naqueles com boa resposta a quimioterapia prévia e com adequado controle da doença local (2B) ${ }^{56}$

\section{Tumor de Wilms}

Os estudos em pacientes com tumor de Wilms recidivado são limitados pelo pequeno número de pacientes e pela dificuldade na randomização. Pacientes que não receberam radioterapia abdominal e com recidiva um ano após o diagnóstico podem ser retratados com quimioterapia e radioterapia Aqueles com fatores de risco como histologia desfavorável e recidiva precoce podem se beneficiar do transplante autólogo (2B). ${ }^{57}$

\section{Doenças não malignas}

\section{Síndromes de falência medular (Tabela 4)}

As indicações de transplante em Pediatria para o tratamento das síndromes de falência medular são semelhantes às indicações em adultos. Entretanto, nos pacientes jovens é muito importante investigar doenças genéticas como anemia de Fanconi, disceratose congênita e síndrome ShwachmanDiamond e, se houver suspeita ou confirmação, o doador aparentado também deve ser investigado. ${ }^{58}$

Atualmente, o transplante alogênico aparentado é indicado já ao diagnóstico da anemia aplásica severa (1A)..$^{59-61}$ Entretanto, o transplante não aparentado é indicado apenas nos pacientes que não respondem a um ciclo de imunossupressão com ciclosporina e globulina antitimocítica. Nas crianças politransfundidas não há consenso de qual seria a melhor droga a ser acrescentada ao regime de condicionamento. Em um único estudo prospectivo randomizado, a adição de globulina antitimocítica à ciclofosfamida não diminuiu a incidência de rejeição, ${ }^{62}$ apesar de esta combinação ser frequentemente utilizada em vários centros de transplante do mundo.

No Brasil, foi adicionado o bussulfano à ciclofosfamida para tentar reduzir a incidência de falha de pega (bussulfano $4 \mathrm{mg} / \mathrm{kg}$ + ciclofosfamida $200 \mathrm{mg} / \mathrm{kg}^{63}$ ou bussulfano $12 \mathrm{mg} / \mathrm{kg}$ + ciclofosfamida $120 \mathrm{mg} / \mathrm{kg}$ ). ${ }^{64,65}$ Após a introdução do bussulfano, houve uma diminuição da rejeição tardia, apesar do aumento da toxicidade precoce, principalmente em crianças de baixa idade.

A experiência brasileira com TCTH para o tratamento da anemia de Fanconi é internacionalmente reconhecida. Os pacientes que desenvolvem aplasia e/ou mielodisplasia devem ser submetidos a transplante em protocolos específicos para evitar a excessiva toxicidade associada a doses habituais de ciclofosfamida. ${ }^{66-68}$ Não existe consenso se os pacientes com anemia de Fanconi com evolução para mielodisplasia e/ou leucemia deveriam ou não receber tratamento quimioterápico pré-transplante. Entretanto, a adição de pequenas 
Tabela 4. Critérios de indicação de transplante de células-tronco hematopoéticas em síndromes de falência medular em Pediatria

\begin{tabular}{|c|c|c|c|}
\hline Doença & Fase da doença/ Critério de indicação & $\begin{array}{l}\text { Transplante } \\
\text { alogênico com } \\
\text { irmão HLA } \\
\text { compatível }\end{array}$ & $\begin{array}{c}\text { Transplante } \\
\text { alogênico com } \\
\text { doador não } \\
\text { aparentado }\end{array}$ \\
\hline \multicolumn{4}{|l|}{ Síndromes de falência medular } \\
\hline Anemia aplásica severa & $\begin{array}{l}\text { Ao diagnóstico } \\
\text { Falha } \mathrm{a} \geq 1 \text { ciclo de imunossupressão com ATG }\end{array}$ & $\begin{array}{l}1 \mathrm{~A} \\
2 \mathrm{~A}\end{array}$ & $\begin{array}{l}\mathrm{NI} \\
2 \mathrm{~A}\end{array}$ \\
\hline Anemia de Fanconi & $\begin{array}{l}\text { Fase de aplasia (preferencial), mielodisplasia ou } \\
\text { leucemia (após quimioterapia) }\end{array}$ & $2 \mathrm{~A}$ & 2B \\
\hline Hemoglobinúria paroxística noturna & $\begin{array}{l}\text { Fase de aplasia (não há comparação com uso de } \\
\text { Eclizumab) }\end{array}$ & $2 \mathrm{~A}$ & $2 \mathrm{~A}$ \\
\hline Disceratose congênita & Fase de aplasia & $3 A$ & 3B \\
\hline Síndrome de Schwachman-Diamond & $\begin{array}{l}\text { Fase de aplasia (preferencial), mielodisplasia ou } \\
\text { leucemia (após quimioterapia) }\end{array}$ & $3 B$ & $3 B$ \\
\hline Síndrome de Blackfan -Diamond & $\begin{array}{l}\text { Crianças }>6 \text { anos sem resposta a corticoide e boa } \\
\text { quelação de ferro }\end{array}$ & $2 \mathrm{~A}$ & $2 \mathrm{~B}$ \\
\hline $\begin{array}{l}\text { Trombocitopenia amegacariocítica } \\
\text { congênita }\end{array}$ & Plaquetopenia grave & 2B & 3B \\
\hline $\begin{array}{l}\text { Síndrome de Kostmann } \\
\text { (Agranulocitose congênita) }\end{array}$ & $\begin{array}{l}\text { Neutropenia irresponsiva a G-CSF ou leucemia } \\
\text { secundária (após quimioterapia) }\end{array}$ & 2B & 2B \\
\hline
\end{tabular}

Obs.: Transplantes autólogos não são realizados no tratamento de falências medulares

doses de radioterapia ao regime de condicionamento pode aumentar a sua chance de sobrevida. ${ }^{68}$ As crianças com Fanconi devem ser seguidas por toda a vida devido ao alto risco de tumores secundários, principalmente em orofaringe.

A hemoglobinúria paroxística noturna é tratada com transplante alogênico aparentado (2A). Não há estudos comparando transplante alogênico não aparentado com tratamento medicamentoso com Eclizumab. ${ }^{69}$

Disceratose congênita é uma das indicações de transplante aparentado (3A) ou não aparentado (3B), mas deve-se ter atenção especial às complicações em vários órgãos e a possível surgimento de tumores a longo prazo..$^{70,71}$

A síndrome Shwachman-Diamond é tratada com transplante aparentado (3B) $;^{72}$ o resultado na fase de aplasia é superior ao obtido na fase de mielodisplasia. ${ }^{73}$ Não deve ser utilizada a irradiação. ${ }^{74}$ Condicionamento ideal é de intensidade reduzida. ${ }^{75}$

Blackfan-Diamond só deve ser tratado com transplante aparentado (2A) ou não aparentado (2B) se a criança não tiver resposta ao corticoide. A quelação de ferro antes do transplante é muito importante. Há alta mortalidade associada aos transplantes não aparentados. ${ }^{76}$

Púrpura amegacariocítica congênita pode ser tratada com transplante aparentado (2B) ou não aparentado (3B), mas não aquelas com trombocitopenia com ausência de rádio que apresentam remissão espontânea nos primeiros anos de vida. ${ }^{77}$

\section{Hemoglobinopatias (Tabela 5)}

A talassemia maior e a anemia falciforme (AF) são doenças hereditárias frequentes que reduzem o tempo e a qualidade de vida do paciente. Até o momento, o TCTH alogênico é a única opção de cura destas doenças. Entretanto, a melhora da qualidade e da efetividade da terapia de suporte usada atualmente, tanto transfusional como farmacológica, deve ser ponderada com os efeitos tardios e risco do TCTH em longo prazo. ${ }^{78}$

Apesar dos resultados do TCTH para ambas as doenças serem muito semelhantes, com sobrevida livre de doença alta, a variabilidade clínica destas duas hemoglobinopatias impõe questionamento da indicação e do momento do procedimento. Pacientes com talassemia maior dependem de programa transfusional continuado com maior risco de desenvolver sobrecarga de ferro, tendo a indicação de TCTH mais consistente. Os pacientes com AF apresentam uma maior variabilidade clínica de gravidade, fazendo com que a indicação de TCTH se limite à presença de sinais de complicações maiores da doença como, por exemplo, o acidente vascular cerebral (AVC)..$^{78,79}$

Existem evidências consistentes para indicar o TCTH com doador familiar compatível para pacientes pediátricos $(<16$ anos) com talassemia maior em programa regular de quelação, apesar de não existirem estudos comparativos em longo prazo com a terapia conservadora atual (2A). Entre os fatores que melhoram a sobrevida estão: idade inferior a 16 
Tabela 5. Critérios de indicação de transplante de células-tronco hematopoéticas emhHemoglobinopatias em pediatria

\begin{tabular}{|c|c|c|c|}
\hline Doença & Fase da doença/ Critério de indicação & $\begin{array}{l}\text { Transplante } \\
\text { alogênico com } \\
\text { irmão HLA } \\
\text { compatível }\end{array}$ & $\begin{array}{l}\text { Transplante } \\
\text { alogênico com } \\
\text { doador não } \\
\text { aparentado }\end{array}$ \\
\hline$\beta$-Talassemia Major & $\begin{array}{l}\text { Idade < } 16 \text { anos em programa regular de quelação com } \\
\text { classificação Pessaro I ou II }\end{array}$ & $2 A$ & $2 \mathrm{~B}$ \\
\hline \multirow[t]{4}{*}{$\begin{array}{l}\text { Doença Falciforme (Anemia falciforme, } \\
\text { doença SC e S - } \beta \text { Talassemia) }\end{array}$} & $\begin{array}{l}\text { Pacientes com uma ou mais complicações } \\
\text { - Crises vaso-oclusivas recorrentes e/ou priapismo } \\
\text { (> } 2 \text { episódios no ano precedente ou no ano anterior ao } \\
\text { início de um programa de transfusão crônica) após uso } \\
\text { de hidroxiureia por > } 6 \text { meses sem resposta ou contra- } \\
\text { indicação ao uso da mesma: }\end{array}$ & \multirow[t]{4}{*}{$2 \mathrm{~A}$} & \multirow[t]{4}{*}{$2 \mathrm{C}$} \\
\hline & $\begin{array}{l}\text { - Vasculopatia cerebral demonstrada por RNM ou } \\
\text { ecodoppler transcraniano e requerendo um programa } \\
\text { de transfusão crônica }\end{array}$ & & \\
\hline & - Doença pulmonar falciforme graus I e II & & \\
\hline & $\begin{array}{l}\text { - Nefropatia falciforme (TFG entre } 30 \% \text { e } 50 \% \text { do } \\
\text { esperado) }\end{array}$ & & \\
\hline
\end{tabular}

Obs.: Classificação de Pessaro: Classe I = sem hepatomegalia, quelação regular e ausência de fibrose portal; Classe II = hepatomegalia, e/ou quelação regular ou ausência de fibrose portal; Classe III = hepatomegalia, quelação irregular e fibrose portal. Transplantes autólogos não são realizados no tratamento de hemoglobinopatias fora de contexto investigacional de terapia gênica

anos; programa de quelação adequado; ausência de fibrose hepática e de hepatomegalia.

A classificação de risco de Pessaro permanece um importante fator para estratificar o risco e definir o melhor condicionamento, estando indicado o TCTH para pacientes com classe 1 e $2 .{ }^{80}$

A anemia falciforme (AF) contrasta com a talassemia pela sua maior variabilidade de manifestações clínicas, que incluem: anemia, crises de dor, síndrome torácica aguda, sequestração esplênica, AVC, disfunção crônica pulmonar e renal, retardo do crescimento, distúrbios neuropsicológicos e mortalidade precoce. Várias medidas de prevenção e suporte têm alterado o curso da doença, como a profilaxia antibacteriana precoce, estimuladores da $\mathrm{HbF}$, como a hidroxiureia e o suporte transfusional. Entretanto a única terapia que provê cura ainda é o TCTH alogênico. ${ }^{79,81-83}$

A compilação dos dados da literatura sugere que o TCTH alogênico com doador compatível aparentado é uma alternativa para o tratamento de pacientes com manifestações clínicas grave decorrentes da doença falciforme (2A). Os critérios de elegibilidade para TCTH em pacientes com AF estão apresentados na Tabela 5. São critérios considerados de exclusão: escore de performance baixo (Lansky ou Karnofsky $<70$ ); hepatite aguda ou evidência de fibrose hepática ou cirrose; insuficiência renal grave (TFG $<30 \%$ ); sequela neurológica funcional grave (mais que hemiplegia isolada); doença pulmonar grave; não adesão ao tratamento.

Apesar dos bons resultados obtidos com TCTH para a cura das hemoglobinopatias, a avaliação e o reconhecimento dos efeitos tardios provocados pelo procedimento e pela doença devem ser cuidadosamente analisados e são essenciais para a decisão de indicar o procedimento, uma vez que são doenças que comprometem a qualidade de vida e a sobrevida somente em longo prazo.

\section{Imunodeficiências (Tabela 6)}

No tratamento das imunodeficiências congênitas, o transplante aparentado ou não está indicado para pacientes com imunodeficiência grave combinada (SCID - 2A; também transplante haploidêntico pela gravidade extrema dos casos), Wiskott-Aldrich (2A), doença granulomatosa crônica (2B), Chediak-Higashi (2B), linfohistiocitose (2A), agranulocitose congênita (2A), deficiência de $\alpha$-IFN (2B), deficiência de adesão leucocitária (2B), deficiência do CD40L (2B) e outras doenças raras (2B). ${ }^{84,85}$

Uma grande preocupação em nossas crianças com imunodeficiência grave combinada é a infecção disseminada pelo bacilo Calmette-Guérin vacinal. ${ }^{86}$ Crianças com suspeita de imunodeficiência, quer por história infecciosa neonatal grave ou por história familiar, devem ter a vacina contra tuberculose adiada até que seja afastado o diagnóstico de imunodeficiência.

\section{Erros inatos do metabolismo (Tabela 7)}

\section{Mucopolissacaridoses}

Erros inatos do metabolismo podem ser tratados com transplante alogênico aparentado ou não em situações específicas. Estes transplantes são de alta complexidade e devem ser realizados em centros com experiência nestas doenças. É possível pesquisar a quantidade de enzima no doador, inclusive sangue de cordão umbilical não aparentado, e escolher o doador com maior nível enzimático. O transplante está indicado nas mucopolissacaridoses MPS $1 \mathrm{H}$ (forma grave de 
Tabela 6. Critérios de indicação de transplante de células-tronco hematopoéticas em imunodeficiências em pediatria

\begin{tabular}{|c|c|c|c|}
\hline Doença & Fase da doença/ Critério de indicação & $\begin{array}{l}\text { Transplante } \\
\text { alogênico com } \\
\text { irmão HLA } \\
\text { compativel }\end{array}$ & $\begin{array}{c}\text { Transplante } \\
\text { alogênico com } \\
\text { doador não } \\
\text { aparentado }\end{array}$ \\
\hline Imunodeficiência combinada grave (SCID) & $\begin{array}{l}\text { Ao diagnóstico } \\
\text { SCID sem células } T \text { ou } B(T-B-) \\
\text { SCID com células } B(T-B+) \\
\text { SCID com deficiência de adenosina deaminase (ADA) } \\
\text { Disgenesia reticular }\end{array}$ & $2 \mathrm{~A}$ & $2 A$ \\
\hline $\begin{array}{l}\text { Imunodeficiências predominantemente } \\
\text { celulares }\end{array}$ & $\begin{array}{l}\text { Ao diagnóstico } \\
\text { Síndrome de Omenn } \\
\text { Deficiência de ZAP-70 } \\
\text { Deficiência da classe II do MHC } \\
\text { Hipoplasia cartilagem-cabelo } \\
\text { Deficiência da purina nucleosídeo fosforilase } \\
\text { Deficiência completa do receptor de } \\
\text { gama-interferon (IFN-y R1 ou R2) }\end{array}$ & $2 \mathrm{~A}$ & $2 \mathrm{~A}$ \\
\hline $\begin{array}{l}\text { Síndrome de Hiper-lgM (deficiência do } \\
\text { ligante do CD40) }\end{array}$ & Ao diagnóstico & $2 \mathrm{~A}$ & $2 \mathrm{~A}$ \\
\hline $\begin{array}{l}\text { Síndrome de } \\
\text { Wiskott-Aldrich }\end{array}$ & Ao diagnóstico & $2 \mathrm{~A}$ & $2 A$ \\
\hline Deficiências do sistema fagocítico & $\begin{array}{l}\text { Doença granulomatosa crônica com infecções graves } \\
\text { Ao diagnóstico } \\
\text { Deficiência de adesão leucocitária } \\
\text { ísíndrome de Chediak-Higashi } \\
\text { Linfohistiocitose familiar } \\
\text { munodeficiência com albinismo parcial (síndrome de } \\
\text { Griscelli) }\end{array}$ & $2 \mathrm{~A}$ & $2 A$ \\
\hline Síndrome IPEX & Ao diagnóstico & $2 \mathrm{~A}$ & $2 \mathrm{~A}$ \\
\hline
\end{tabular}

Obs.: Transplantes autólogos não são realizados no tratamento de imunodeficiências fora de contexto investigacional de terapia gênica.

Tabela 7. Critérios de indicação de transplante de células-tronco hematopoéticas em erros Inatos do metabolismo em pediatria

\begin{tabular}{|c|c|c|c|}
\hline Doença & Fase da doença/ Critério de indicação & $\begin{array}{c}\text { Transplante alogênico } \\
\text { com irmão HLA } \\
\text { compatível }\end{array}$ & $\begin{array}{c}\text { Transplante alogênico } \\
\text { com doador não } \\
\text { aparentado }\end{array}$ \\
\hline \multicolumn{4}{|l|}{ Mucopolissacaridoses (MPS) } \\
\hline MPS $1 \mathrm{H}$ - Hurler & $\begin{array}{l}\text { Forma grave com QI > } 70 \text { e abaixo dos } 2 \text { anos } \\
\text { de vida }\end{array}$ & $2 \mathrm{~A}$ & $2 \mathrm{~A}$ \\
\hline MPS VI - Síndrome de Maroteaux-Lamy & Forma grave & $2 \mathrm{~A}$ & $2 \mathrm{~A}$ \\
\hline MPS VII - Síndrome de Sly & Ao diagnóstico & $2 A$ & $2 \mathrm{~A}$ \\
\hline Outras MPS & & Não há consenso & Não há consenso \\
\hline Adrenoleucodistrofia ligada ao $X$ & $\begin{array}{l}\text { Escore de Loes } \geq 1 \text { e }<10 \text {, QI de } \\
\text { atuação }>80 \text {, déficit neurológico } \leq 1\end{array}$ & $2 \mathrm{~A}$ & $2 \mathrm{~A}$ \\
\hline \multirow[t]{2}{*}{ Leucodistrofia metacromática } & $\begin{array}{l}\text { Forma infantil tardia: apenas em pacientes } \\
\text { assintomáticos }\end{array}$ & 2C & $2 \mathrm{C}$ \\
\hline & $\begin{array}{l}\text { Forma juvenil ou adulta: apenas em pacientes } \\
\text { com déficit neurológico } \leq 1\end{array}$ & 2B & 2B \\
\hline \multirow[t]{2}{*}{$\begin{array}{l}\text { Doença de Krabbe (leucodistrofia de } \\
\text { células globoides) }\end{array}$} & $\begin{array}{l}\text { Forma infantil: apenas transplante neonatal } \\
\text { Forma tardia: apenas em pacientes }\end{array}$ & $2 \mathrm{~A}$ & $2 \mathrm{~A}$ \\
\hline & com déficit neurológico $\leq 1$ & 2B & $2 \mathrm{~B}$ \\
\hline Osteopetrose & Pacientes sem degeneração neurológica & $2 \mathrm{~A}$ & $2 \mathrm{C}$ \\
\hline
\end{tabular}

Obs.: Transplantes autólogos não são realizados no tratamento de erros inatos do metabolismo 
Hurler com QI>70 e menos de 2 anos (2A); não há consenso sobre a indicação de TMO nas outras mucopolissacaridoses. ${ }^{87,88}$

\section{Adrenoleucodistrofia ligada ao $X$}

A adrenoleucodistrofia ligada ao X é um distúrbio do metabolismo dos ácidos graxos de cadeia muito longa, sendo uma doença de peroxissomos. Esta doença produz insuficiência adrenal e desmielinização. Em alguns pacientes, o quadro pode ficar restrito aos nervos periféricos, porém, em outros pacientes, a doença evoluiu para a forma cerebral. Após o início da forma cerebral há uma progressiva deterioração das funções neurológicas, sendo que, em cinco anos, cerca de $50 \%$ dos pacientes já faleceram. ${ }^{89}$

Um estudo publicado em 2007 por Mahmood et al. ${ }^{90}$ comparou, retrospectivamente, um grupo de trinta pacientes com forma cerebral precoce de adrenoleucodistrofia a 19 pacientes submetidos ao TCTH. A sobrevida do grupo transplantado em cinco anos foi de $95 \%$ contra $54 \%$ dos não transplantados $(\mathrm{p}=0.006)$.

$\mathrm{O}$ transplante está indicado para pacientes com escore de Loes $>1$ e $<10$, QI de atuação (performance) $>80$ e déficit neurológico $<1(2 \mathrm{~A})$. Pacientes transplantados com doença avançada não se beneficiaram do procedimento e tem alta mortalidade. ${ }^{91}$ No Brasil, a experiência com transplante foi sumarizada por Jardim et al. ${ }^{92}$ mostrando uma sobrevida de cinco dos sete pacientes transplantados.

\section{Leucodistrofia metacromática}

Há raros relatos do uso do TCTH. Somente pacientes com boa performance neuropsicológica e independência nas atividades do dia a dia devem ser transplantados. A forma juvenil tardia também pode beneficiar-se do transplante, desde que seguindo as mesmas recomendações (2 C). ${ }^{93,94}$

Outras doenças de depósito perixossomal e lisossomal

Outras doenças, como a leucodistrofia de células globoides (Doença de Krabbe), podem ser transplantadas para evitar a degeneração neurológica, valendo a mesma orientação de submeter ao transplante pacientes com boa performance neuropsicológica (2 B)..$^{95,96}$

\section{Osteopetrose - forma infantil maligna}

O TCTH aparentado (2A) ou não aparentado (2B) deve ser indicado para lactentes com a forma infantil maligna desde que não exista degeneração neurológica e retardo mental importante. Os melhores resultados são obtidos quando utilizamos doadores familiares totalmente compatíveis (mais de $70 \%$ de sobrevida global). ${ }^{97,98}$

\section{Conclusões}

Este artigo fez uma revisão ampla das doenças mais frequentemente transplantadas em Pediatria, sendo as indi- cações atualizadas para a data de sua publicação. Segundo orientação da Sociedade Brasileira de Transplante de Medula Óssea, as indicações serão revistas a cada dois anos. Ressaltamos mais uma vez que esta publicação não deve ser utilizada para aplicação direta no cuidado do paciente sem levar em conta características da doença, do doador e fatores de risco do próprio paciente. Este trabalho não deve ainda ser utilizado como documento que limite o acesso do paciente ao transplante adequadamente indicado.

\begin{abstract}
The Brazilian Bone Marrow Transplant Society (SBTMO) held its First Meeting on Bone Marrow Transplant Guidelines in 2009. A working group of hematologists and oncologists with experience in pediatrics was formed to review evidence-based indications for pediatric transplants. Scientific publications were carefully assessed and, for each disease, the evidence for recommendation (from $A$ to $C$ ) and the quality of the evidence (from 1 to 3) were defined. The recommendations include malignant and non-malignant hematological diseases, solid tumors, immunodeficiency, and storage diseases treated with hematopoietic stem cell transplants: either autologous or allogeneic from matched sibling donors or unrelated donors (adults or umbilical cord blood). Guidelines for reducedintensity transplants, manipulated grafts or partially compatible donors were not included as there are no uniformly accepted recommendations. All indications are based on the best current knowledge which may change over time. Thus, this review should not be directly applied to patient care without taking into account the disease, donor and patient characteristics. Additionally, this paper should not be used as a document to limit patient access to transplant if correctly indicated. In this review we also point out differences between transplantation in adults and children and make some specific recommendations for pediatric transplants. Rev. Bras. Hematol. Hemoter. 2010;32(3):225-239.
\end{abstract}

Key words: Transplantation; bone marrow; pediatrics; leukemia; neoplasms; stem cells.

Nota: Este artigo é o resultado do trabalho do grupo de oncologistas e hematologistas com experiência em pediatria, participantes do I Encontro de Diretrizes Brasileiras em Transplante de Células-Tronco Hematopoéticas da Sociedade Brasileira de Transplante de Medula Óssea, realizado em junho de 2009, no Rio de Janeiro.

$\mathrm{O}$ artigo foi avaliado pelos coordenadores das Diretrizes do Transplante de Medula Óssea da Sociedade Brasileira de Transplante de Medula Óssea, Luis Fernando Bouzas, Prof. Julio Cesar Voltarelli e Nelson Hamerschlak, e publicado após avaliação e revisão do editor, Milton Artur Ruiz.

\section{Agradecimentos}

Agradecemos a colaboração de Laura Bannach Jardim e Lauro José Gregianin. 


\section{Referências Bibliográficas}

1. Jones R, Nieto Y, Rizzo JD, Wall D, Wingard JR, McCarthy P Jr, et al. Steering Committee for Evidence-Based Reviews of the American Society for Blood and Marrow Transplantation. The evolution of the evidence-based review: evaluating the science enhances the art of medicine--statement of the Steering Committee for Evidence-Based Reviews of the American Society for Blood and Marrow Transplantation. Biol Blood Marrow Transplant. 2005;11(11):819-22.

2. Pappas PG, Kauffman CA, Andes D, Benjamin DK Jr, Calandra $\mathrm{TF}$, Edwards JE Jr, et al. Infectious Diseases Society of America. Clinical practice guidelines for the management of candidiasis: 2009 update by the Infectious Diseases Society of America. Clin Infect Dis. 2009;48(5):503-35.

3. Canadian Task Force on the Periodic Health Examination. The periodic health examination. Can Med Assoc J. 1979;121(9):1193254.

4. Ljungman $\mathrm{P}$, Bregni $\mathrm{M}$, Brune $\mathrm{M}$, Cornelissen $\mathrm{J}$, de Witte $\mathrm{T}$, Dini G, et al; European Group for Blood and Marrow Transplantation. Allogeneic and autologous transplantation for haematological diseases, solid tumours and immune disorders: current practice in Europe 2009. Bone Marrow Transplant. $2010 ; 45(2): 219-34$

5. Eapen M, Horowitz MM, Klein JP, Champlin RE, Loberiza FR $\mathrm{Jr}$, Ringdén $\mathrm{O}$, et al. Higher mortality after allogeneic peripheral-blood transplantation compared with bone marrow in children and adolescents: the Histocompatibility and Alternate Stem Cell Source Working Committee of the International Bone Marrow Transplant Registry. J Clin Oncol. 2004;22(24):4872-80.

6. Lee SJ, Klein J, Haagenson M, Baxter-Lowe LE, Confer DL, Eapen $\mathrm{M}$, et al. High-resolution donor-recipient HLA matching contributes to the success of unrelated donor marrow transplantation. Blood. 2007;110(13):4576-83.

7. Barker JN, Scaradavou A, Stevens CE. Combined effect of total nucleated cell dose and HLA match on transplantation outcome in 1061 cord blood recipients with hematologic malignancies. Blood. 2010;115(9):1843-9.

8. Balduzzi A, Valsecchi M, Uderzo C, De Lorenzo P, Klingebiel T, Peters $\mathrm{C}$, et al. Chemotherapy versus allogeneic transplantation for very high-risk childhood acute lymphoblastic leukaemia in first complete remission: comparison by genetic randomisation in an international prospective study. Lancet. 2005;366 (9486):635-42

9. Eapen M, Rubinstein P, Zhang MJ, Stevens C, Kurtzberg J, Scaradavo $A$, et al. Outcomes of transplantation of unrelated donor umbilical cord blood and bone marrow in children with acute leukaemia: a comparison study. Lancet. 2007;369(9577):1947-54.

10. Aricò M, Valsecchi MG, Camitta B, Schrappe M, Chessells J, Baruchel A, et al. Outcome of treatment in children with Philadelphia chromosome-positive acute lymphoblastic leukemia. N Engl J Med. 2000;342(14):998-1006.

11. Satwani P, Sather H, Ozkaynak F, Heerema NA, Schultz KR, Sanders $\mathrm{J}$, et al. Allogeneic bone marrow transplantation in first remission for children with ultra-high-risk features of acute lymphoblastic leukemia: A childrens oncology group study report. Biol Blood Marrow Transplant. 2007;13(2):218-27.

12. Peters C, Schrauder A, Schrappe M, von Stackelberg A, Stary J, Yaniv I, et al, on behalf of the BFM Study Group, the IBFM-Study Group and the Paediatric Disease Working Party of the EBMT. Allogeneic haematopoietic stem cell transplantation in children with acute lymphoblastic leukaemia: the BFM/IBFM/EBMT concepts. Bone Marrow Transplant. 2005;35:S9-S11.
13. Gaynon PS, Harris RE, Altman AJ, Bostrom BC, Breneman JC, Hawks $\mathrm{R}$, et al. Bone marrow transplantation versus prolonged intensive chemotherapy for children with acute lymphoblastic leukemia and an initial bone marrow relapse within 12 months of the completion of primary therapy: Childrens Oncology Group study CCG-1941. J Clin Oncol. 2006;24(19):3150-6.

14. Harrison CJ, Hills RK, Moorman AV, Grimwade DJ, Hann I, Webb DK, et al. Cytogenetics of childhood acute myeloid leukemia: United Kingdom Medical Research Council Treatment trials AML 10 and 12. J Clin Oncol. 2010 Jun 1;28(16):2674-81

15. Barbaric D, Alonzo TA, Gerbing RB, Meshinchi S, Heerema NA, Barnard DR, et al. Minimally differentiated acute myeloid leukemia (FAB AML-M0) is associated with an adverse outcome in children: a report from the Childrens Oncology Group, studies CCG-2891 and CCG-2961. Blood. 2007;109(6):2314-21.

16. Barnard DR, Alonzo TA, Gerbing RB, Lange B, Woods WG; Childrens Oncology Group. Comparison of childhood myelodysplastic syndrome, AML FAB M6 or M7, CCG 2891: report from the Childrens Oncology Group. Pediatr Blood Cancer. 2007;49(1):17-22.

17. Sievers EL, Lange BJ, Alonzo TA, Gerbing RB, Bernstein ID, Smith FO, et al. Immunophenotypic evidence of leukemia after induction therapy predicts relapse: results from a prospective Childrens Cancer Group study of 252 patients with acute myeloid leukemia. Blood. 2003;101(9):3398-406.

18. Woods WG, Neudorf S, Gold S, Sanders J, Buckley JD, Barnard DR, et al; Childrens Cancer Group. A comparison of allogeneic bone marrow transplantation, autologous bone marrow transplantation, and aggressive chemotherapy in children with acute myeloid leukemia in remission. Blood. 2001;97(1):56-62.

19. Hasle H, Niemeyer CM, Chessells JM, Baumann I, Bennett JM, Kerndrup G, et al. A pediatric approach to the WHO classification of myelodysplastic and myeloproliferative diseases. Leukemia. 2003;17(2):277-82. Review.

20. Yoshimi A, Baumann I, Führer M, Bergsträsser E, Göbel U, Sykora $\mathrm{KW}$, et al. Immunosuppressive therapy with anti-thymocyte globulin and cyclosporine A in selected children with hypoplastic refractory cytopenia. Haematologica. 2007;92(3):397-400.

21. Strahm B, Locatelli F, Bader P, Ehlert K, Kremens B, Zintl F, et al. Reduced intensity conditioning in unrelated donor transplantation for refractory cytopenia in childhood. Bone Marrow Transplant. 2007;40(4):329-33.

22. Pearson HA, Lobel JS, Kocoshis SA, Naiman JL, Windmiller J, Lammi AT, et al. A new syndrome of refractory sideroblastic anemia with vacuolization of marrow precursors and exocrine pancreatic dysfunction. J Pediatr. 1979;95(6):976-84.

23. Yusuf U, Frangoul HA, Gooley TA, Woolfrey AE, Carpenter PA, Andrews RG, et al. Allogeneic bone marrow transplantation in children with myelodysplastic syndrome or juvenile myelomonocytic leukemia: the Seattle experience. Bone Marrow Transplant. 2004;33(8):805-14.

24. Locatelli F, Nöllke P, Zecca M, Korthof E, Lanino E, Peters C, et al; European Working Group on Childhood MDS; European Blood and Marrow Transplantation Group. Hematopoietic stem cell transplantation (HSCT) in children with juvenile myelomonocytic leukemia (JMML): results of the EWOG-MDS/EBMT trial. Blood. 2005;105(1):410-9.

25. Pulsipher MA. Treatment of CML in pediatric patients: should imatinib mesylate (STI-571, Gleevec) or allogeneic hematopoietic cell transplant be front-line therapy? Pediatr Blood Cancer. 2004;43(5):523-33.

26. Handgretinger R, Kurtzberg J, Egeler RM. Indications and donor selections for allogeneic stem cell transplantation in children 
with hematologic malignancies. Pediatr Clin North Am. 2008;55 (1):71-96.

27. Cwynarski K, Roberts IA, Iacobelli S, van Biezen A, Brand R, Devergie A, et al; Paediatric and Chronic Leukaemia Working Parties of the European Group for Blood and Marrow Transplantation. Stem cell transplantation for chronic myeloid leukemia in children. Blood. 2003;102(4):1224-31.

28. Ouachée-Chardin M, Elie C, de Saint Basile G, Le Deist F, Mahlaoui $\mathrm{N}$, Picard C, et al. Hematopoietic stem cell transplantation in hemophagocytic lymphohistiocytosis: a single-center report of 48 patients. Pediatrics. 2006;117(4):e743-50.

29. Schellong G, Dörffel W, Claviez A. Salvage therapy of progressive and recurrent Hodgkins disease: results from a multicenter study of the pediatric DAL/GPOH-HD study group. J Clin Oncol. 2005; 23(25):6181-9.

30. Claviez A, Sureda A, Schmitz N. Haematopoietic SCT for children and adolescents with relapsed and refractory Hodgkins lymphoma. Bone Marrow Transplant. 2008;42 Suppl 2:S16-24.

31. Galvão de Castro C Jr, Gregianin LJ, Brunetto AL. Autologous hematopoietic stem cell transplantation in children with relapse or refractory Hodgkin disease. J Pediatr Hematol Oncol. 2006; 28(11):772.

32. Lieskovsky YE, Donaldson SS, Torres MA, Wong RM, Amylon MD, Link MP, et al. High-dose therapy and autologous hematopoietic stem-cell transplantation for recurrent or refractory pediatric Hodgkins disease: results and prognostic indices. J Clin Oncol. 2004;22(22):4532-40.

33. Sureda A, Robinson S, Canals C, Carella AM, Boogaerts MA, Caballero D, et al. Reduced-intensity conditioning compared with conventional allogeneic stem-cell transplantation in relapsed or refractory Hodgkins lymphoma: an analysis from the Lymphoma Working Party of the European Group for Blood and Marrow Transplantation. J Clin Oncol. 2008;26(3):455-62.

34. Claviez A, Canals C, Dierickx D, Stein J, Badell I, Pession A, et al; Lymphoma and Pediatric Diseases Working Parties. Allogeneic hematopoietic stem cell transplantation in children and adolescents with recurrent and refractory Hodgkin lymphoma: an analysis of the European Group for Blood and Marrow Transplantation. Blood. 2009;114(10):2060-7.

35. Ladenstein R, Pearce R, Hartmann O. High-dose chemotherapy with autologous bone marrow rescue in children with poor-risk Burkitts lymphoma: a report from the European Lymphoma Bone Marrow Transplantation Registry. Blood 1997;90(8): 2921-30.

36. Griffin TC, Weitzman S, Weinstein H, Chang M, Cairo M, Hutchison $\mathrm{R}$, et al; Childrens Oncology Group. A study of rituximab and ifosfamide, carboplatin, and etoposide chemotherapy in children with recurrent/refractory B-cell (CD20+) non-Hodgkin lymphoma and mature B-cell acute lymphoblastic leukemia: a report from the Childrens Oncology Group. Pediatr Blood Cancer. 2009; 52(2):177-81.

37. Bradley MB, Cairo MS. Stem cell transplantation for pediatric lymphoma: past, present and future. Bone Marrow Transplant. 2008;41(2):149-58.

38. Brugières L, Quartier P, Le Deley MC, Pacquement H, Perel Y, Bergeron $\mathrm{C}$, et al. Relapses of childhood anaplastic large-cell lymphoma: treatment results in a series of 41 children - a report from the French Society of Pediatric Oncology. Annals Oncol. 2000;11:53-8.

39. Cesaro S, Pillon M, Visintin G, Putti MC, Gazzola MV, D'Amore E, et al. Unrelated bone marrow transplantation for high-risk anaplastic large cell lymphoma in pediatric patients: a single Center case series. Eur J Haematol 2005;75:22-6.
40. Woessmann W, Peters C, Lenhard M, Burkhardt B, Sykora KW, Dilloo D, et al. Allogeneic haematopoietic stem cell transplantation in relapsed or refractory anaplastic large cell lymphoma or children and adolescents - a Berlin-Frankfurt-Münster group report. Br J Haematol. 2006;133(2):176-82.

41. Burkhardt B, Reiter A, Landmann E, Lang P, Lassay L, Dickerhoff $\mathrm{R}$, et al. Poor outcome for children and adolescents with progressive disease or relapse of lymphoblastic lymphoma: a report from the Berlin-Frankfurt-Muenster group. J Clin Oncol. 2009;27(20):3363-9.

42. Levine JE, Harris RE, Loberiza FR Jr, Armitage JO, Vose JM, Van Besien $\mathrm{K}$, et al; Lymphoma Study Writing Committee, International Bone Marrow Transplant Registry and Autologous Blood and Marrow Transplant Registry. A comparison of allogeneic and autologous bone marrow transplantation for lymphoblastic lymphoma. Blood. 2003;101(7):2476-82.

43. Castro Jr CG, Mendes WL, Borsatto ML, Castro HC, Melaragno R, Odone Filho V, et al. Autologous stem cell transplantation for the treatment of pediatric solid tumors in Brazil. J Ped Hematol Oncol. $2005 ; 27: 467$.

44. Castro Jr CG, Seber A, Mendes WL, Castro HC, Borsatto ML, Gregianin LJ, et al. Autologous stem cell transplantation for the treatment of pediatric solid tumors in Brazil. Biol Blood Marrow Transplant. 2004;10:78-9.

45. Matthay KK, Reynolds CP, Seeger RC, Shimada H, Adkins ES, Haas-Kogan $\mathrm{D}$, et al. Long-term results for children with high-risk neuroblastoma treated on a randomized trial of myeloablative therapy followed by 13-cis-retinoic acid: a childrens oncology group study. J Clin Oncol. 2009;27(7):1007-13.

46. Ladenstein R, Pötschger U, Hartman O, Pearson AD, Klingebiel T, Castel V, et al; EBMT Paediatric Working Party. 28 years of highdose therapy and SCT for neuroblastoma in Europe: lessons from more than 4000 procedures. Bone Marrow Transplant. 2008;41 Suppl 2:S118-27.

47. Kondagunta GV, Motzer RJ. Chemotherapy for advanced germ cell tumors. J Clin Oncol. 2006 Dec 10;24(35):5493-502.

48. Gilheeney SW, Khakoo Y, Souweidane M, Wolden S, Boulad F, Dunkel IJ. Thiotepa/ topotecan/ carboplatin with autologous stem cell rescue in recurrent/ refractory/ poor prognosis pediatric malignancies of the central nervous system. Pediatr Blood Cancer. 2010;54(4):591-5.

49. Marachelian A, Butturini A, Finlay J. Myeloablative chemotherapy with autologous hematopoietic progenitor cell rescue for childhood central nervous system tumors. Bone Marrow Transplant. 2008; 41(2):167-72.

50. Gururangan S, McLaughlin C, Quinn J, Rich J, Reardon D, Halperin EC, et al. High-dose chemotherapy with autologous stem-cell rescue in children and adults with newly diagnosed pineoblastomas. J Clin Oncol. 2003;21(11):2187-91.

51. Dhall G, Grodman H, Ji L, Sands S, Gardner S, Dunkel IJ, et al. Outcome of children less than three years old at diagnosis with non-metastatic medulloblastoma treated with chemotherapy on the "Head Start" I and II protocols. Pediatr Blood Cancer. 2008; 50(6):1169-75.

52. Butturini AM, Jacob M, Aguajo J, Vander-Walde NA, Villablanca J, Jubran R, et al. High-dose chemotherapy and autologous hematopoietic progenitor cell rescue in children with recurrent medulloblastoma and supratentorial primitive neuroectodermal tumors: the impact of prior radiotherapy on outcome. Cancer. 2009;115(13):2956-63.

53. Dunkel IJ, Chan HS, Jubran R, Chantada GL, Goldman S, Chintagumpala $\mathrm{M}$, et al. High-dose chemotherapy with autologous hematopoietic stem cell rescue for stage 4B retinoblastoma. Pediatr Blood Cancer. $2010 ; 55(1): 149-52$. 
54. Juergens C, Weston C, Lewis I, Whelan J, Paulussen M, Oberlin O, et al. Safety assessment of intensive induction with vincristine, ifosfamide, doxorubicin, and etoposide (VIDE) in the treatment of Ewing tumors in the Euro-Ewing 99 clinical trial. Pediatr Blood Cancer. 2006;47(1):22-9.

55. Oberlin O, Rey A, Desfachelles AS, Philip T, Plantaz D, Schmitt C, et al; Société Française des Cancers de 1'Enfant. Impact of highdose busulfan plus melphalan as consolidation in metastatic Ewing tumors: a study by the Société Française des Cancers de 1'Enfant. J Clin Oncol. 2006;24(24):3997-4002.

56. Al-Faris N, Al Harbi T, Goia C, Pappo A, Doyle J, Gassas A. Does consolidation with autologous stem cell transplantation improve the outcome of children with metastatic or relapsed Ewing sarcoma? Pediatr Blood Cancer. 2007;49(2):190-5.

57. Dallorso S, Dini G, Faraci M, Spreafico F; EBMT Paediatric Working Party. SCT for Wilms tumour. Bone Marrow Transplant. 2008;41 Suppl 2:S128-30.

58. Mehta P, Locatelli F, Stary J, Smith FO. Bone marrow transplantation for inherited bone marrow failure syndromes. Pediatr Clin North Am. 2010;57(1):147-70.

59. Locasciulli A, Oneto R, Bacigalupo A, Socié G, Korthof E, Bekassy A, et al; Severe Aplastic Anemia Working Party of the European Blood and Marrow Transplant Group. Outcome of patients with acquired aplastic anemia given first line bone marrow transplantation or immunosuppressive treatment in the last decade: a report from the European Group for Blood and Marrow Transplantation (EBMT). Haematologica. 2007; 92(1):11-8.

60. Schrezenmeier H, Passweg JR, Marsh JC, Bacigalupo A, Bredeson $\mathrm{CN}$, Bullorsky E, et al. Worse outcome and more chronic GVHD with peripheral blood progenitor cells than bone marrow in HLAmatched sibling donor transplants for young patients with severe acquired aplastic anemia. Blood. 2007;110(4):1397-400.

61. Perez-Albuerne ED, Eapen M, Klein J, Gross TJ, et al. Outcome of unrelated donor stem cell transplantation for children with severe aplastic anemia. Br J Haematol. 2008; 141(2):216-23.

62. Champlin RE, Perez WS, Passweg JR, Klein JP, Camitta BM, Gluckman E, et al. Bone marrow transplantation for severe aplastic anemia: a randomized controlled study of conditioning regimens. Blood. 2007;109(10):4582-5.

63. Dulley FL. Bussulfano e ciclofosfamida como condicionamento para o transplante de medula óssea da anemia aplástica grave. Rev Bras Hematol Hemoter. 2001;23(1):59-60.

64. Silva LCL, Pasquini R. Análise da rejeição nos pacientes transplantados por anemia aplástica severa condicionados com ciclofosfamida ou a associação desta ao bussulfano. Rev Bras Hematol Hemoter. 2005;27(1):5-11.

65. Dulley FL. Bussulfano e ciclofosfamida no condicionamento do transplante de medula óssea para anemia aplástica grave. Rev Bras Hematol Hemoter. 2005;27(1):3.

66. Bonfim CM, de Medeiros CR, Bitencourt MA, Zanis-Neto J, Funke VA, Setubal DC, et al. HLA-matched related donor hematopoietic cell transplantation in 43 patients with Fanconi anemia conditioned with $60 \mathrm{mg} / \mathrm{kg}$ of cyclophosphamide. Biol Blood Marrow Transplant. 2007;13(12):1455-60.

67. de Medeiros CR, Bitencourt MA, Zanis-Neto J, Maluf EC, Carvalho DS, Bonfim CS, et al. Allogeneic hematopoietic stem cell transplantation from an alternative stem cell source in Fanconi anemia patients: analysis of 47 patients from a single institution. Braz J Med Biol Res. 2006;39(10):1297-304.

68. MacMillan ML, Wagner JE. Haematopoeitic cell transplantation for Fanconi anaemia - when and how? Br J Haematol. 2010; 149 (1):14-21.
69. Brodsky RA. How I treat paroxysmal nocturnal hemoglobinuria. Blood. 2009;113(26):6522-7.

70. Calado RT, Young NS. Telomere diseases. N Engl J Med. 2009; 361(24):2353-65.

71. Bonfim CMS, Bitencourt MA, Funke VA, Setubal DC, Ruiz J, Zanis-Neto $\mathrm{J}$, et al. Bone marrow transplantation for dyskeratosis congenita: Analysis of complications and long term follow-up. Biol Blood Marrow Transplant. 2005;11(2), Suppl 1:36.

72. Donadieu J, Michel G, Merlin E, Bordigoni P, Monteux B, Beaupain $\mathrm{B}$, et al. Hematopoietic stem cell transplantation for ShwachmanDiamond syndrome: experience of the French neutropenia registry. Bone Marrow Transplant. 2005;36(9):787-92.

73. Fleitz J, Rumelhart S, Goldman F, Ambruso D, Sokol RJ, Pacini D, et al. Successful allogeneic hematopoietic stem cell transplantation (HSCT) for Shwachman-Diamond syndrome. Bone Marrow Transplant. 2002;29(1):75-9.

74. Cesaro S, Oneto R, Messina C, Gibson BE, Buzyn A, Steward C, et $a l$; EBMT Severe Aplastic Anaemia and Paediatric Diseases Working Party. Haematopoietic stem cell transplantation for Shwachman-Diamond disease: a study from the European Group for blood and marrow transplantation. $\mathrm{Br} \mathrm{J}$ Haematol. 2005;131(2):231-6.

75. Bhatla D, Davies SM, Shenoy S, Harris RE, Crockett M, Shoultz L, et al. Reduced-intensity conditioning is effective and safe for transplantation of patients with Shwachman-Diamond syndrome. Bone Marrow Transplant. 2008;42(3):159-65.

76. Roy V, Pérez WS, Eapen M, Marsh JC, Pasquini M, Pasquini R, et al; Non-Malignant Marrow Disorders Working Committee of the International Bone Marrow Transplant Registry. Bone marrow transplantation for diamond-blackfan anemia. Biol Blood Marrow Transplant. 2005;11(8):600-8.

77. Geddis AE. Congenital amegakaryocytic thrombocytopenia and thrombocytopenia with absent radii. Hematol Oncol Clin North Am. 2009;23(2):321-31.

78. Bhatia M, Walters MC. Hematopoietic cell transplantation for thalassemia and sickle cell disease: past, present and future. Bone Marrow Transplant. 2008;41(2):109-17.

79. Simões BP, Pieroni F, Barros G, Machado CL, Cançado RD, Salvino MA, et al. Consenso Brasileiro em Transplante de Células-Tronco Hematopoéticas: Comitê de Hemoglobinopatias. Rev. Bras. Hematol. Hemoter. 2010;32(Supl.1):46-53.

80. Lucarelli G, Andreani M, Angelucci E. The cure of thalassemia by bone marrow transplantation. Blood Rev. 2002;16(2):81-5.

81. Walters MC, Patience M, Leisenring W, Eckman JR, Buchanan GR, Rogers ZR, et al. Barriers to bone marrow transplantation for sickle cell anemia. Biol Blood Marrow Transplant. 1996;2(2):100-4.

82. Amrolia PJ, Almeida A, Halsey C, Roberts IA, Davies SC. Therapeutic challenges in childhood sickle cell disease. Part 1: current and future treatment options. Br J Haematol. 2003; 120(5):725-36.

83. Amrolia PJ, Almeida A, Davies SC, Roberts IA. Therapeutic challenges in childhood sickle cell disease. Part 2: a problemorientated approach. Br J Haematol. 2003;120(5):737-43.

84. Szabolcs P, Cavazzana-Calvo M, Fischer A, Veys P. Bone marrow transplantation for primary immunodeficiency diseases. Pediatr Clin North Am. 2010;57(1):207-37.

85. Filipovich A. Hematopoietic cell transplantation for correction of primary immunodeficiencies. Bone Marrow Transplant. 2008;42 Suppl 1:S49-S52.

86. Gouveia RV, Bonfim CMS, Ginani VC, Zecchin VG, Carlesse F, Carvalho CR, et al. Hematopoietic stem cell transplantation for patients with severe combined immunodeficiency and disseminated Bacillus Calmette-Guérin infections. Biol Blood Marrow Transplant. 2010;16(2):S262. 
87. Lange MC, Teive HA, Troiano AR, Bitencourt M, Funke VA, Setúbal $\mathrm{DC}$, et al. Bone marrow transplantation in patients with storage diseases: a developing country experience. Arq Neuropsiquiatr. 2006;64(1):1-4

88. Prasad VK, Mendizabal A, Parikh SH, et al. Unrelated donor umbilical cord blood transplantation for inherited metabolic disorders in 159 patients from a single center: influence of cellular composition of the graft on transplant outcome. Blood. 2008 1;112(7):2979-89

89. Peters C, Charnas LR, Tan Y, Ziegler RS, Shapiro EG, DeFor T, et al. Cerebral X-linked adrenoleukodystrophy: the international hematopoietic cell transplantation experience from 1982 to 1999. Blood. 2004;104(3):881-8.

90. Mahmood A, Raymond GV, Dubey P, Peters C, Moser HW. Survival analysis of haematopoietic cell transplantation for childhood cerebral X-linked adrenoleukodystrophy: a comparison study. Lancet Neurol. 2007;6(8):687-92.

91. Moser HW, Raymond GV, Dubey P. Adrenoleukodystrophy: new approaches to a neurodegenerative disease. JAMA. 2005; 294 (24):3131-4.

92. Jardim LB, Silva ACF, Blank D, Villanueva MM, Renck L, Costa MLB, et al. X-linked adrenoleukodystrophy: Clinical course and minimal incidence in South Brazil. Brain Development. 2010; 32(3):180-90.

93. Peters C, Steward CG; National Marrow Donor Program; International Bone Marrow Transplant Registry; Working Party on Inborn Errors, European Bone Marrow Transplant Group. Hematopoietic cell transplantation for inherited metabolic diseases: an overview of outcomes and practice guidelines. Bone Marrow Transplant. 2003;31(4):229-39.

94. Görg M, Wilck W, Granitzny B, Suerken A, Lukacs Z, Ding X, et al. Stabilization of juvenile metachromatic leukodystrophy after bone marrow transplantation: a 13-year follow-up. J Child Neurol. 2007;22(9):1139-42.

95. Krivit W, Peters C, Shapiro EG. Bone marrow transplantation as effective treatment of central nervous system disease in globoid cell leukodystrophy, metachromatic leukodystrophy, adrenoleukodystrophy, mannosidosis, fucosidosis, aspartylglucosaminuria, Hurler, Maroteaux-Lamy, and Sly syndromes, and Gaucher disease type III. Curr Opin Neurol. 1999;12:167-76.

96. Peters C, Steward CG; National Marrow Donor Program; International Bone Marrow Transplant Registry; Working Party on Inborn Errors, European Bone Marrow Transplant Group. Hematopoietic cell transplantation for inherited metabolic diseases: an overview of outcomes and practice guidelines. Bone Marrow Transplant. 2003;31(4):229-39.

97. Steward CG. Hematopoietic Stem Cell Transplantation for osteopetrosis. Pediatr Clin North Am 2010;57(1):171-80

98. Driessen GJ, Gerritsen EJ, Fischer A, Fasth A, Hop WC, Veys P, et al. Long-term outcome of haematopoietic stem cell transplantation in autosomal recessive osteopetrosis: an EBMT report. Bone Marrow Transplant. 2003;32(7):657-63.

Avaliação: Editor e dois revisores externos

Conflito de interesse: sem conflito de interesse

Recebido: 22/05/2010

Aceito: 22/06/2010 